\title{
Improved Reflectance and Stability of Mo/Si Multilayers
}

S. Bait, J. Alameda, T. Barbee, M. Clift, J.A. Folta, B. Kauffman, E. Spiller

This article was submitted to

Soft X-Ray and Extreme Ultra-Violet Imaging Systems II, San Diego, California, July 31 - August 1, 2001

\section{U.S. Department of Energy}

\section{October 22, 2001}

\section{Lawrence}

Livermore

National

Laboratory 


\section{DISCLAIMER}

This document was prepared as an account of work sponsored by an agency of the United States Government. Neither the United States Government nor the University of California nor any of their employees, makes any warranty, express or implied, or assumes any legal liability or responsibility for the accuracy, completeness, or usefulness of any information, apparatus, product, or process disclosed, or represents that its use would not infringe privately owned rights. Reference herein to any specific commercial product, process, or service by trade name, trademark, manufacturer, or otherwise, does not necessarily constitute or imply its endorsement, recommendation, or favoring by the United States Government or the University of California. The views and opinions of authors expressed herein do not necessarily state or reflect those of the United States Government or the University of California, and shall not be used for advertising or product endorsement purposes.

This is a preprint of a paper intended for publication in a journal or proceedings. Since changes may be made before publication, this preprint is made available with the understanding that it will not be cited or reproduced without the permission of the author.

This report has been reproduced directly from the best available copy.

Available electronically at http://www.doe.gov/bridge

Available for a processing fee to U.S. Department of Energy and its contractors in paper from

U.S. Department of Energy

Office of Scientific and Technical Information

P.O. Box 62

Oak Ridge, TN 37831-0062

Telephone: (865) 576-8401

Facsimile: (865) 576-5728

E-mail: reports@adonis.osti.gov

Available for the sale to the public from

U.S. Department of Commerce

National Technical Information Service

5285 Port Royal Road

Springfield, VA 22161

Telephone: (800) 553-6847

Facsimile: (703) 605-6900

E-mail: orders@ntis.fedworld.gov

Online ordering: http://www.ntis.gov/ordering.htm

OR

Lawrence Livermore National Laboratory

Technical Information Department's Digital Library

http://www.llnl.gov/tid/Library.html 


\author{
Improved reflectance and stability of Mo/Si multilayers \\ Saša Bajt ${ }^{{ }^{*}}$, J. Alameda ${ }^{\mathrm{a}}$, T. Barbee Jr. ${ }^{\mathrm{a}}$, M. Clift ${ }^{\mathrm{b}}$, J. A. Folta ${ }^{\mathrm{a}}$, B. Kauffman ${ }^{\mathrm{a}}$, E. Spiller ${ }^{\mathrm{a}}$ \\ ${ }^{a}$ Lawrence Livermore National Laboratory, 7000 East Avenue, Livermore, CA 94450, USA. \\ ${ }^{\mathrm{b}}$ Sandia National Laboratory, Livermore, CA 94550, USA.
}

\begin{abstract}
Commercial EUV lithographic systems require multilayers with higher reflectance and better stability then that published to date. Interface-engineered Mo/Si multilayers with $70 \%$ reflectance at $13.5 \mathrm{~nm}$ wavelength (peak width of $0.545 \mathrm{~nm}$ ) and $71 \%$ at $12.7 \mathrm{~nm}$ wavelength (peak width of $0.49 \mathrm{~nm}$ ) were developed. These results were achieved with 50 bilayers. These new multilayers consist of Mo and Si layers separated by thin boron carbide layers. Depositing boron carbide on interfaces leads to reduction in silicide formation on the Mo-on-Si interfaces. Bilayer contraction is reduced by $30 \%$ implying that there is less intermixing of $\mathrm{Mo}$ and $\mathrm{Si}$ to form silicide. As a result the Mo-on-Si interfaces are sharper in interface-engineered multilayers than in standard $\mathrm{Mo} / \mathrm{Si}$ multilayers. The optimum boron carbide thicknesses have been determined and appear to be different for Mo-on-Si and Si-on-Mo interfaces. The best results were obtained with $0.4 \mathrm{~nm}$ thick boron carbidé layer on the Mo-on-Si interface and $0.25 \mathrm{~nm}$ thick boron carbide layer on the Si-on-Mo interface. Increase in reflectance is consistent with multilayers with sharper and smoother interfaces.
\end{abstract}

A significant improvement in oxidation resistance of EUV multilayers has been achieved with ruthenium terminated $\mathrm{Mo} / \mathrm{Si}$ multilayers. The best capping layer design consists of a Ru layer separated from the last $\mathrm{Si}$ layer by a boron carbide layer. This design achieves high reflectance and the best oxidation resistance in a water vapor (i.e. oxidation) environment: Electron beam exposures of 4.5 hours in the presence of $5 \times 10^{-7}$ torr water vapor partial pressure show no measurable reflectance loss and no increase in the oxide thickness of $\mathrm{Ru}$. terminated multilayers. Longer exposures in different environments are necessary to test lifetime stability of many years.

KEYWORDS: Multilayers, reflectivity, interfaces, capping layers, oxidation resistance, Extreme ultraviolet (EUV) lithography

\title{
1. INTRODUCTION
}

Extreme ultraviolet lithography (EUVL), a leading next generation lithography technology, is based on all reflective optics operating at a wavelength of $13.4 \mathrm{~nm}$. High quality $\mathrm{Mo} / \mathrm{Si}$ reflective coatings are the enabling technology for EUVL. In the past few years dramatic improvements in deposition control systems have produced multilayer coatings with unprecedented thickness accuracy and reproducibility, essential to meet the stringent specifications of commercial EUVL tools ${ }^{1-3}$. At Lawrence Livermore National Laboratory (LLNL), accurate multilayer coatings were successfully applied on many large, and often deeply curved, optical substrates including two sets consisting of projection optics and numerous sets of condenser optics. Outstanding levels of wavelength matching and thickness uniformity were achieved, and the added figure error was maintained within specifications, meaning that the multilayer coatings did not contribute any aberrations to the system performance of the Engineering Test Stand (ETS) camera ${ }^{4-6}$. Now that full field EUV imaging has been demonstrated with the ETS tool the emphasis is to make this technology commercially viable. Commercial EUVL tools, planned to be available in 2006, need to have a throughput of $80300 \mathrm{~mm}$ wafers per hour. Higher reflectance of the multilayer coatings would have a substantial impact on the throughput and economic viability of EUVL tools. Table 1 shows the EUVL multilayer roadmap that the Virtual National Laboratory (VNL) is pursuing to meet commercial requirements. The first column describes the issues to be solved, the second column shows the current status and the third and the forth column show the requirements for the $\beta$-tool in 2004 and for the commercial tools in 2006, respectively. In this paper we will focus on the first four rows that cover peak reflectance and lifetime of these coatings. The requirement for the peak reflectance of the imaging optic is at least $70 \%$ with minimal reflectance loss ( $1.6 \%$ absolute) over 5 years. The reflectance loss on condenser optics is allowed to be larger over a shorter lifetime, based on the assumption that condenser optics is cheaper and replaceable.

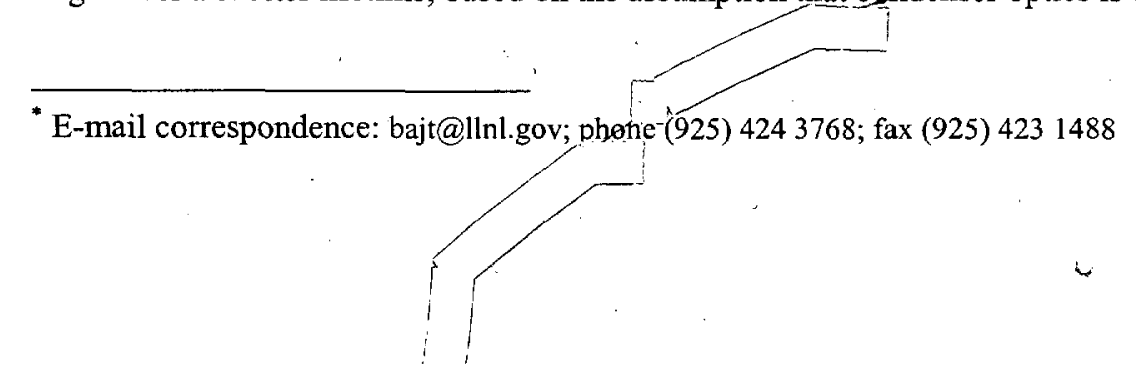




\begin{tabular}{|c|c|c|c|}
\hline Issue & $\begin{array}{l}\text { Current status } \\
2001\end{array}$ & $\begin{array}{l}\beta \text {-tool } \\
2004\end{array}$ & $\begin{array}{c}\text { Commercial tool } \\
2006\end{array}$ \\
\hline $\begin{array}{l}\text { Peak Reflectance - } \\
\text { optics }\end{array}$ & $65 \%$ & $68 \%$ & $70 \%$ \\
\hline $\begin{array}{l}\text { Lifetime (Imaging } \\
\text { Optics) }\end{array}$ & Unknown & $1.6 \%{ }^{*} / 3$ years & $1.6 \% \star / 5 y e a r s$ \\
\hline $\begin{array}{l}\text { Lifetime (First } \\
\text { Condenser Optic) }\end{array}$ & Unknown & $10 \% * /$ year & $10 \% * /$ year \\
\hline $\begin{array}{c}\text { Lifetime (Other } \\
\text { Condenser Optics) }\end{array}$ & Unknown & $2.5 \% * /$ year & $2.5 \%{ }^{*} /$ year \\
\hline $\begin{array}{l}\text { Max Operation Temp } \\
\text { (Imaging Optics) }\end{array}$ & $25^{\circ} \mathrm{C}$ & $25^{\circ} \mathrm{C}$ & $25^{\circ} \mathrm{C}$ \\
\hline $\begin{array}{l}\text { Mask Rapid Thermal } \\
\text { Cycle }\end{array}$ & $150^{\circ} \mathrm{C},<2 \mathrm{~min}$ & $200^{\circ} \mathrm{C},<2 \mathrm{~min}$ & $200^{\circ} \mathrm{C},<2 \mathrm{~min}$ \\
\hline $\begin{array}{l}\text { Max Operation Temp } \\
\therefore \text { (Mask Plane) }\end{array}$ & $25^{\circ} \mathrm{C}$ & $30^{\circ} \mathrm{C}$ & $35^{\circ} \mathrm{C}$ \\
\hline MLAdded Figure Error & $0.1 \mathrm{~nm} \mathrm{rms}$ & $0.05 \mathrm{~nm} \mathrm{rms}$ & $0.025 \mathrm{~nm} \mathrm{rms}$ \\
\hline $\begin{array}{l}\text { Relative Optical } \\
\text { Throughput }{ }^{\star \star}\end{array}$ & 1.0 & 1.5 & 2.0 \\
\hline
\end{tabular}

Table 1: EUVL multilayer roadmap. The numbers labeled with an asterix $\left({ }^{*}\right)$ are relative percents and the relative optical throughput numbers $\left({ }^{* *}\right)$ are calculated for a system assuming 10 multilaver-coated surfaces.

In the first part of this paper we present the design of $\mathrm{Mo} / \mathrm{Si}$ interface-engineered multilayers. The sharper interfaces of these multilayers lead to increased reflectance. The second part of the paper describes different multilayer capping layers and the stability results from electron beam exposures. The multilayer deposition process for all results presented here, and the electron beam exposure procedure are outlined in section 2 . The results on interface-engineered multilayers and on capping lyaers presented in section 3 and 4, respectively and the shirt summary is given in section 5 .

\section{EXPERIMENT}

2.1. Deposition system

All the multilayers used in this study were deposited using the DC-magnetron sputtering machine shown in Figure 1. Upgrades of the machine have taken place since it was last described ${ }^{1}$. The deposition system now contains four sputtering guns mounted on the bottom of the chamber and spaced 90 degrees apart. Two of the sputtering guns are rectangular $(12.7 \mathrm{x}$ $25.4 \mathrm{~cm})$ placed $180 \mathrm{deg}$ apart and two are circular $(100 \mathrm{~mm})$ also placed $180 \mathrm{deg}$ apart. The substrates, which are spun during the depositions, are facing down and are affixed to the platter, which rotates over the sputtering targets. The individual layer thickness is controlled by the platter angular velocity. Two cryo-pumps are used to evacuate the chamber to the operating pressure of at most $2 \times 10^{-7}$ torr. Ultrahigh purity Ar gas at 1 mTorr was used to sputter the Si (360W), Mo (170W), boron carbide (100W) and Ru (50W) targets. A typical deposition run is done in less than 1 hour and up to two deposition 
runs per day are easily achieved. Interface engineered multilayers were fabricated utilizing large, rectangular targets (Mo and $\mathrm{Si}$ ) and two circular boron carbide $\left(\mathrm{B}_{4} \mathrm{C}\right)$ targets. For the capping layer work we replaced one of the boron carbide targets with a Ru target (Fig. 1). Further upgrades will be carried out so that capped interface-engineered multilayers can be manufactured.

\subsection{Electron beam exposures and Auger electron spectroscopy}

An Auger microprobe PHI660 was used to test capping layers by exposing them to the electron beam in a controlled environment. The electron beam size on the sample was $1 \times 1 \mathrm{~mm}$. The energy of the electrons was kept constant at $2 \mathrm{kV}$ and the current density of incident electrons was $5 \mu \mathrm{A} / \mathrm{mm}^{2}$. This corresponds to a current density of $\approx 2.5 \mu \mathrm{A} / \mathrm{mm}^{2}$ of secondary electrons assuming that each primary electron emits 0.5 secondary electron. To produce the same secondary current from incident EUV photons one would need about $25 \mathrm{~mW} / \mathrm{mm}^{2}$ of EUV irradiance. Our typical exposure time with the electron beam was 4.5 hours and all the exposure experiments were done in $5 \times 10^{-7}$ Torr of water vapor partial pressure as measured by a SRS200 RGA monitoring mass 18 .

Auger electron spectroscopy was used to identify the elemental composition of the multilayers. An additional ion beam gun was used to remove less than a monolayer of material from the surface at a time and to continue to monitor the composition and the chemistry from the surface as this surface moved into the sample. A PHI 660 Scanning Auger microprobe was operated at $5 \mathrm{kV}$ and $75 \mathrm{nA}$ and the beam was rastered over a $50 \mu \mathrm{m} \times 50 \mu \mathrm{m}$ area at 30 degrees from normal incidence. A PHI Duoplasmatron ion gun was operated at $2 \mathrm{kV}$ and $8.0 \mathrm{nA}$ current and the beam was rastered over a $300 \mu \mathrm{m} \times 300 \mu \mathrm{m}$ area at a 45 degree angle. Sputter rates within the multilayer of $\mathrm{Mo}$ and $\mathrm{Si}$ were adjusted for a multilayer rate of $6.9 \mathrm{~nm} / \mathrm{layer}$. No attempt was made to adjust sputter rates for the $\mathrm{Ru}$ or $\mathrm{B}_{4} \mathrm{C}$ capping layers.

\subsection{Characterization techniques (X-ray diffraction, reflectometry, TEM)}

The sputtering rates were calibrated by varying the velocity of the platter over the sources at a constant power and determining the multilayer periods by fitting the Bragg peaks in the X-ray diffraction spectra. X-ray diffraction measurements were performed using a Rigaku DMAX-IIB diffractometer with a $\mathrm{Cu} \mathrm{K}_{\alpha}$ rotating anode source $(\lambda \equiv 0.154 \mathrm{~nm})$ : The small angle $\mathrm{X}$-ray diffraction measurements were obtained over the angular range of $\theta-2 \theta$ between $1^{\circ}-11^{\circ}$.

Reflectance of the multilayers was measured with a synchrotron-based reflectometer at the Advanced Light Source (ALS), beamline 6.3.2. (Lawrence Berkeley National Laboratory). This reflectometer has been designed for the characterization of multilayer-coated EUVL optics and has high spectral purity, high stability and small beam diameter. The detailed description of the beamline can be found elsewhere? ${ }^{7}$. The wavelength precision of this reflectometer is $0.002 \mathrm{~nm}$ and the reflectance results are repeatable within $\pm 0.2 \%$.

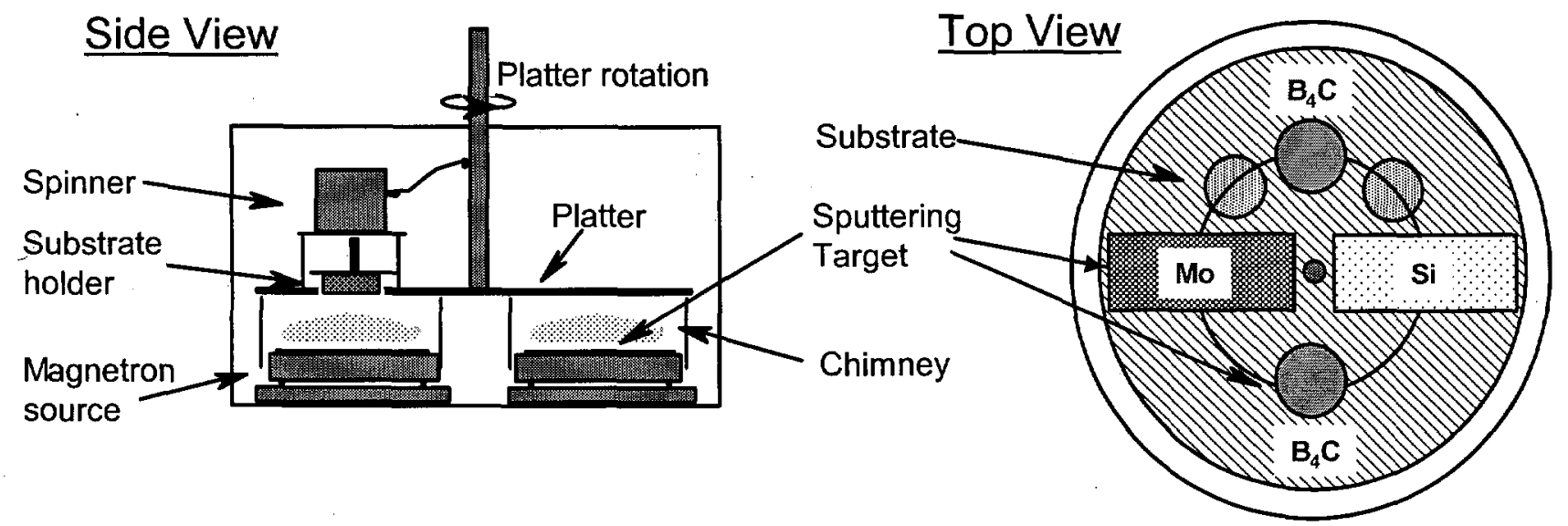

Figure 1: Layout of the DC magnetron sputter system used to deposit multilayer coatings. 
Transmission electron microscopy (TEM) was used to yerify the quality of the interfaces and the microstructure of the interface-engineered multilayers. High resolution images of the samples were obtained using a Philips CM300 FEG microscope operated at $300 \mathrm{keV}$ with a point-to-point resolution of $0.1 \mathrm{~nm}$. Specimen preparation and operation of the microscope have been reported elsewhere ${ }^{8}$.

\section{INTERFACE-ENGINEERED MULTILAYERS}

In the past few years much work has been done in optimizing the deposition conditions to maximize reflectance of Mo/Si multilayers ${ }^{4,9}$. By optimizing $\Gamma$ (Mo thickness/period thickness) and increasing the number of bilayers to 60 we can achieve reflectivity up to $68.8 \%$ at $13.4 \mathrm{~nm}$. However, increasing the reflectance even further requires a major change in the multilayer design or in the deposition process. For example, introduction of low $Z$ material barriers ${ }^{10}$, ion beam etching ${ }^{11}$, substrate heating ${ }^{12}$ and pulsed laser deposition ${ }^{13}$ are just few techniques that are currently being pursued to achieve this goal.

What are the major imperfections in the multilayer that reduce the reflectance? One of them is the formation of surface oxide. This is impossible to avoid completely because the multilayers get exposed to air, but choosing a material to terminate the multilayer that forms a thinner, less absorbing surface oxide than Si may mitigate this effect. Another source of imperfections is the quality of the interfaces between the Mo and Si layers. In standard Mo/Si multilayers the interfaces are not abrupt at all. Polycrystalline Mo layers and amorphous Si layers are separated by asymmetric silicide layers. The exact silicide composition and its compositional gradient across the layer thickness are still subjects of debate. However, the silicide formation is accompanied by a multilayer period contraction. It is well known that to achieve a certain period thickness one needs to add about an extra $0.52 \mathrm{~nm}$ per bilayer of bulk material in the deposition process to compensate for contraction due to silicide formation. Interestingly, the silicide layer thicknesses are interface dependent. For example, the silicide thickness on the Mo-on-Si interface is at least two times thicker than the silicide thickness on the Si-on-Mo interface. The appearance of the asymmetry in the silicide thickness is associated with a phase transition from amorphous to crystalline structure in Mo layers ${ }^{14}$. Roughness of interfaces is yet another source of imperfections that lowers the multilayer reflectance. However, some studies suggest that interfacial roughness is negligible for optimized sputtering conditions ${ }^{15}$. We have identified a parameter space where the roughness increases dramatically due to amorphous to crystalline transition in Mo layers ${ }^{14}$. Fortunately in an optimized EUV multilayer the Mo thickness is well above that transition.

The approach we took to improve the reflectance of EUV multilayers was to engineer the interfaces to minimize silicide formation at interfaces. The idea is to limit the inter-diffusion of Mo and Si by using a third material as a diffusion barrier and which is EUV transparent (Fig. 2). This idea was recently used by other authors to improve thermal stability of the

\section{Standard Mo/Si multilayer}

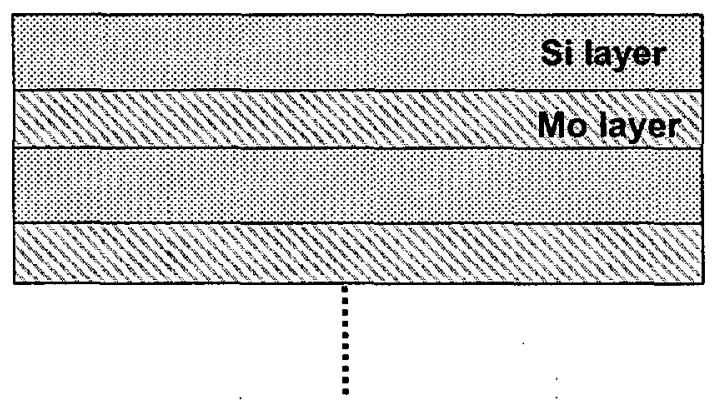

Interface-engineered multilayer

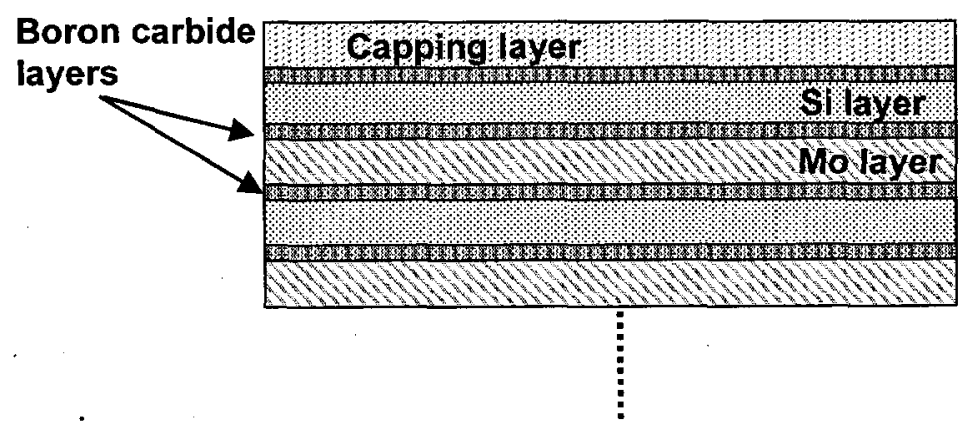

Figure 2: Ideal standard Mo/Si multilayers (a) consist of alternating Mo and Si layers and are terminated with Si layer. Ideal interface-engineered multilayers (b) consist of Mo and Si layers separated with thin boron carbide interfaces. They are terminated with an oxidation resistant capping layer such as ruthenium. However, the interface-engineered multilayers in this paper are terminated with Si layer. 
multilayers but always on the expense of slightly lower reflectivity ${ }^{3,10}$. In our study we used boron carbide as diffusion barrier material. Boron carbide is a low $\mathrm{Z}$ material that reduces the silicide formation and increases the reflectance but also improves heat resistance of the multilayers. Figure 2 shows a Mo/Si multilayer that consists of Mo and Si layers and is terminated with $\mathrm{Si}$ layer. In the following we will call such multilayers standard $\mathrm{Mo} / \mathrm{Si}$ multilayers. The multilayers with Mo and Si layers separated with thin boron carbide layers will be called interface-engineered multilayers.

\subsection{Experimental results}

To optimize the thickness of boron carbide on each interface we made a series of deposition runs. By varying boron carbide thickness on selected interface (either Mo-on-Si or Si-on-Mo or both) we could directly monitor its effect on silicide formation by measuring the total contraction of the multilayer period thickness. We define the contraction, $\Delta \Lambda$, as:

$$
\Delta \Lambda=\Lambda_{c a l c}-\Lambda_{\text {meas }}
$$

where $\Lambda_{\text {calc }}$ is the calculated multilayer period thickness based on the bulk sputtering rates and $\Lambda_{\text {meas }}$ is the measured multilayer period thickness using small angle $\mathrm{x}$-ray diffraction data. The thickness of the silicide interlayer can be measured directly via the contraction:

$$
\Delta \Lambda=\alpha \cdot t
$$

if the parameter $\alpha$ is known. This parameter $\alpha$ was deduced from experimental data. The most likely silicide that forms on the interfaces is the silicide with the lowest heat of formation $\left(\mathrm{MoSi}_{2}\right)$ and for which $\alpha=0.38^{16}$.

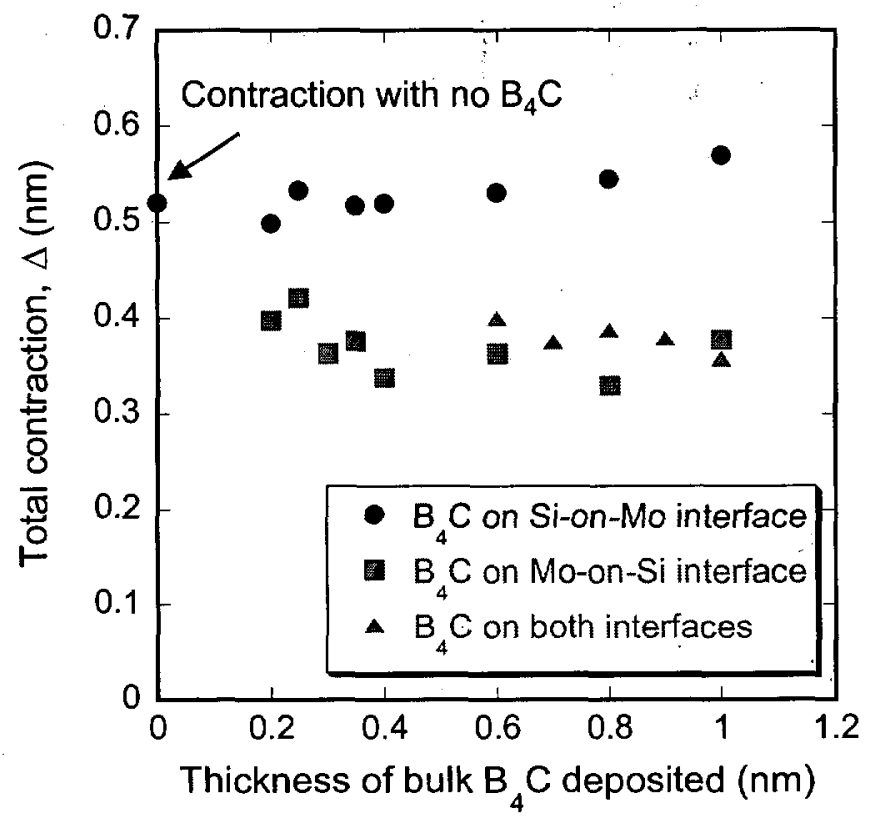

Figure 3: The contraction of the multilayer period is about $0.52 \mathrm{~nm}$ per bilayer for a $\mathrm{Mo} / \mathrm{Si}$ multilayer with no boron carbide on the interfaces. Boron carbide on the Mo-on-Si interface reduces the contraction of the multilayer to about 0.36 $\mathrm{nm}$ per bilayer for a range of boron carbide thicknesses (squares). No change in the contraction of the multilayer period is observed for boron carbide deposited on the Si-on-Mo interface when compared to the $\mathrm{Mo} / \mathrm{Si}$ multilayer with no boron carbide interfaces. The contraction of the multilayer period for multilayers with boron carbide deposited on both interfaces (triangles) is the same as for boron carbide on the Mo-on-Si interface. 


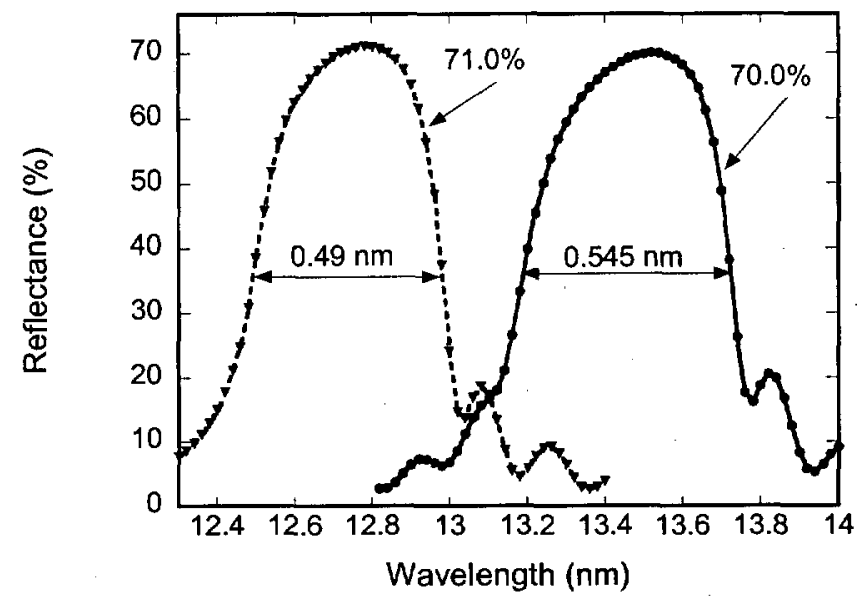

Figure 4: Measured reflectance of interface-engineered multilayers reflecting at $13.5 \mathrm{~nm}$ and at $12.7 \mathrm{~nm}$, respectively. Measurements were done at 5 degrees off normal. Both multilayers consist of 50 bilayers $\mathrm{Mo} / \mathrm{Si}$ multilayer with boron carbide interfaces. The thickness of boron carbide on the Mo-on-Si interface is $0.4 \mathrm{~nm}$ and on the Si-on-Mo interface is $0.25 \mathrm{~nm}$. The reflectance curve of one multilayer has a peak value of $70.0 \%$ at $13.5 \mathrm{~nm}$ and of the other multilayer has a peak value of $71.0 \%$ at $12.7 \mathrm{~nm}$, respectively. The spectral bandwidth of these mirrors, measured at full width at halfmaximum (FWHM) is $0.545 \mathrm{~nm}$ and $0.49 \mathrm{~nm}$, respectively.

In Figure 3 we plot the total contraction as a function of the thickness of bulk boron carbide thickness. Also shown is the contraction in standard Mo/Si multilayer with no boron carbide on interfaces. Application of boron carbide on Mo-on-Si interface substantially decreased the contraction, especially for boron carbide thickness of $0.4 \mathrm{~nm}$ and higher. The contraction was reduced from $0.52 \mathrm{~nm} /$ bilayer to about $0.36 \mathrm{~nm} /$ bilayer. This implies that the deposition of boron carbide on Mo-on-Si interface reduced the formation of silicide but did not completely prevent it. However, when we applied boron carbide on Sion-Mo interface no change in contraction was observed. When we deposited boron carbide on both interfaces the contraction was reduced by the same amount as for Mo-on-Si interface. Therefore, a $0.36 \mathrm{~nm} /$ bilayer contraction was used in interfaceengineered multilayer design.

Knowing bulk sputtering rates of $\mathrm{Mo}, \mathrm{Si}$, boron carbide and the total contraction we were able to design multilayers for a particular wavelength. The optimum thicknesses for $13.4 \mathrm{~nm}$ wavelength multilayer are the following: $\left[\mathrm{Si}(4.37 \mathrm{~nm}) / \mathrm{B}_{4} \mathrm{C}(0.4\right.$ $\left.\mathrm{nm}) / \mathrm{Mo}(2.25 \mathrm{~nm}) / \mathrm{B}_{4} \mathrm{C}(0.25 \mathrm{~nm})\right]_{50}+\mathrm{Si}(4.2 \mathrm{~nm})$. Seventy percent multilayers at $13.5 \mathrm{~nm}$ and $\mathrm{FWHM}$ of $0.545 \mathrm{~nm}$ were achieved with 50 bilayers using this design. For a EUV optical system with 9 reflective surfaces this new multilayer would increase the optical throughput by more than $50 \%$ compared to our best standard Mo/Si multilayers $(68.2 \%$ at $13.4 \mathrm{~nm}$ with $0.533 \mathrm{~nm}$ FWHM). The optical throughput is proportional to:

$$
\int R(\lambda)^{n} d \lambda
$$

with $\mathrm{R}$ being a reflectance curve of the multilayer in the EUV wavelength region and $\mathrm{n}$ the number of reflective mirrors in the system.

High reflectance multilayers have been achieved reproducibly on superpolished $\mathrm{Si}(100)$ wafers and on $2.5 \mathrm{~cm}$ diameter flat silica substrates. However, the EUV multilayer roadmap calls for $70 \%$ reflectance multilayer coatings at $13.4 \mathrm{~nm}$ on optics for commercial tools. These optical substrates will consist of either Zerodur or ULE, both low expansion materials that should prevent aberrations due to thermal load. It is currently a considerable challenge to polish optical substrates that meet the roughness specifications in the low, middle and high frequency range simultaneously. The reflectance is especially sensitive to the roughness in the high frequency range $\left(0.001-0.05 \mathrm{~nm}^{-1}\right)$. Studies in which Zerodur substrates were measured for their high frequency roughness before and after the standard Mo/Si multilayer coating showed that the peak 
reflectance decreases by about $2 \%$ (absolute) for each additional $0.1 \mathrm{~nm}$ high frequency roughness ${ }^{17}$. Ideally the substrate should have $0.1 \mathrm{~nm}$ rms high frequency roughness or less to achieve $70 \%$ reflectance.

\section{CAPPING LAYERS}

High reflectance multilayers are of no use to commercial tools if their performance is not stable as a function of EUV exposure. Hence, reflectance stability of EUV multilayers exposed to EUV radiation in the presence of environmental contaminants is of great concern. Many environmental factors contribute to the loss in the multilayer reflectance over time. The most important ones are oxidation due to water vapor and EUV light or molecular oxygen and EUV light, carbon contamination from outgassing, debris from the source and increased interdiffusion in the multilayers at elevated temperatures. In this paper we propose a solution that addresses the reflectance loss due to oxidation. The solution is a capping layer that acts as an effective oxidation barrier when the multilayer is exposed to the EUV light in the presence of water vapor. So far, most of the studies done on EUV multilayer stability involved multilayers that were terminated with $\mathrm{Si}^{1,4,18-20}$. These studies on $\mathrm{Si}$ capped multilayers show good reflectance stability for multilayers exposed to EUV light in vacuum $^{19,20}$, however, in the presence of EUV light and water vapor the reflectance decreases due to increase in the surface oxide layer thickness ${ }^{21}$. It is believed that upon the irradiation of the mirror with the EUV light the low energy secondary electrons are created and that these secondary electrons are the causing the major damage to the surface of the multilayers. The mechanism on how these electrons interact with water molecules from the environment and what exactly is happening on the surface of the multilayer is not understood yet. However, so far all the existing experimental data suggest that Si capping layer is not an adequate protection against oxidation. Therefore, the lifetime of the multilayers is probably the highest risk item for the EUVL multilayer coatings (Table 1). It is crucial to find a capping layer material that is oxidation resistant, forms a sharp and stable interface with the material underneath and has good optical properties in the EUV region. Little or no experimental work has been published on alternative capping layer materials even though many have been proposed based on their optical properties ${ }^{22}$. Once a good capping layer material has been found the challenge is to test it and project its stability for continuous exposure for long periods of time based on accelerated, short time experiments. The study presented here is based on accelerated electron beam exposures.

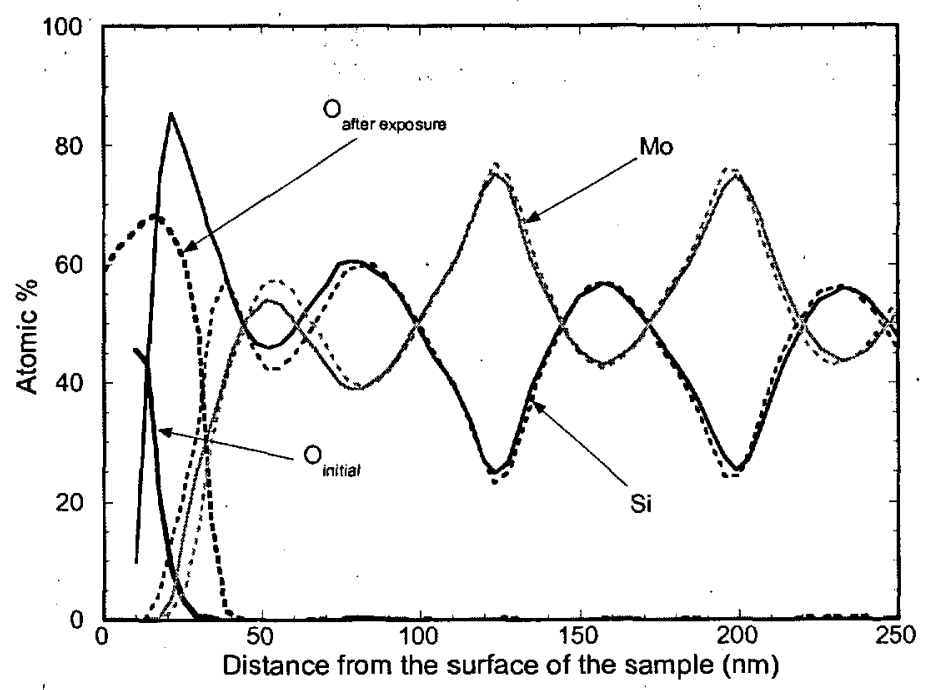

Figure 5: Auger depth profile of Si capped multilayer before (solid lines) and after the exposure to the electron beam (dashed lines) 


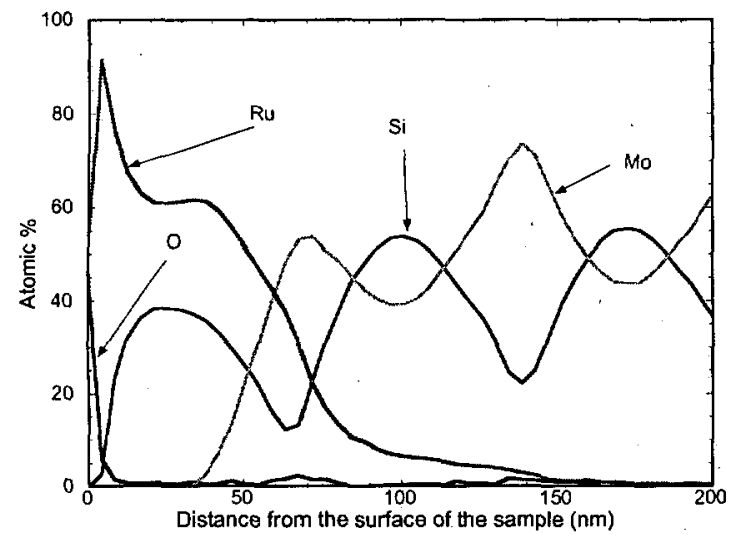

(a)

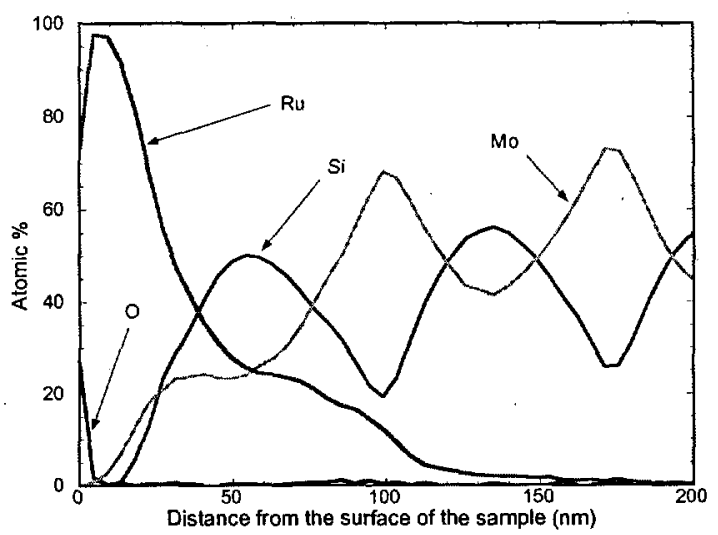

(b)

Figure 6: Depth profiles obtained with Auger spectroscopy on Ru capped multilayers. Ruthenium was deposited directly on the top of the last Si layer in (a) and separated with a thin Mo layer in case (b).

\subsection{Experimental results}

The electron beam experiments were done in the Auger electron microprobe as described in section 2.2. All multilayers in this study were exposed to the same dose. The 4.5 hour exposure with the electron beam corresponds to about 48 hours of EUV exposure on imaging optic for full power EUVL commercial tool with the throughput of $80300 \mathrm{~mm}$ wafers per hour. These exposures were done at a constant water vapor partial pressure of $5 \times 10^{-7}$ Torr. This was the highest water vapor pressure at which we could operate the electron gun with sufficient stability.

All the multilayers in this study consisted of a standard 40 bilayer $\mathrm{Mo} / \mathrm{Si}$ multilayer but had different capping layers. Ruthenium was selected as the most promising candidate for oxidation barrier. Preliminary studies on single, thick Ru films showed thin oxide layer formation on the surface of this metal whose thickness remained unchanged if exposed to the electron beam in the presence of water vapor ${ }^{23}$. We studied stability of $\mathrm{Ru}$ capped multilayers by measuring the reflectance before and after the electron beam exposure and by analyzing the depth profiles with Auger spectroscopy. Three different capping layer designs have been proposed and tested. A Si capped multilayer was used as a reference.

\subsubsection{Si cap}

A standard Mo/Si multilayer with 40 bilayers, a period thickness of $6.9 \mathrm{~nm}$ and $\Gamma$ of 0.42 was capped with a $4.2 \mathrm{~nm}$ thick Si layer. The initial reflectance was $66.6 \%$ at $13.4 \mathrm{~nm}$. After the exposure the reflectance dropped to $64.9 \%$. No change in the peak wavelength was detected. Auger spectroscopy was used to measure depth profile of different elements (Fig. 5) before and after the exposure. Based on the periodicity of Mo and Si peaks, which remains constant, we can measure the change in thickness of the surface oxide and monitor oxygen diffusion into the multilayer. Before the exposure the oxygen could be detected about $1 \mathrm{~nm}$ deep into the sample. After the exposure the oxygen layer is much thicker. Part of it is due to the growth of an additional surface oxide (about $1 \mathrm{~nm}$ ) and part of it is diffusion of oxygen into the silicon layer (about $2 \mathrm{~nm}$ ).

\subsubsection{Ru on $\mathrm{Si}$}

A standard Mo/Si multilayer was terminated with a Si layer on the top of which we deposited $2.3 \mathrm{~nm} \mathrm{Ru}$. The initial reflectance was $65.5 \%$ at $13.45 \mathrm{~nm}$. The reflectance of one month-old multilayer was $65.2 \%$ at $13.45 \mathrm{~nm}$. The reflectance in the exposed area decreased to $64.53 \%$ and no peak wavelength change was observed. Auger spectra of the multilayer show less than $1 \mathrm{~nm}$ thick Ru oxide (Fig. 6a). Most of the Ru seems to react with the last Si layer to form a ruthenium silicide.

\subsubsection{Ru on Mo}

To control the interdiffusion between $\mathrm{Ru}$ and $\mathrm{Si}$ we deposited a thin layer of Mo between these two layers. The standard $\mathrm{Mo} / \mathrm{Si}$ multilayer was terminated with $\mathrm{Si}$ on the top of which we deposited $1.3 \mathrm{~nm}$ thick Mo layer and $2.3 \mathrm{~nm}$ thick Ru layer. The initial reflectance was relatively low $(62.0 \%$ at $13.34 \mathrm{~nm})$ because' the last absorber layer, which consists of $\mathrm{Mo}$ and $\mathrm{Ru}$, is too thick for positive interference with the multilayer underneath. However, the Auger spectra of the multilayer before the exposure shows that the interdiffusion between $\mathrm{Ru}$ and $\mathrm{Si}$ is largely suppressed (Fig. 6b). Also, the reflectance after the 


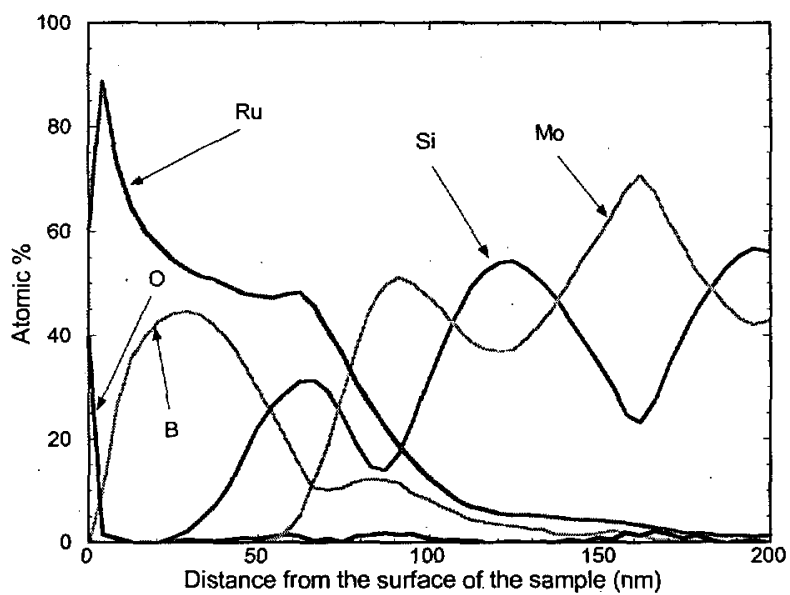

Figure 7: Ru on B4C on Si capping layer

exposure is less $(0.6 \%)$ than in Ru on Si capped multilayer. No change in the peak wavelength was detected. Multilayers with initial reflectance of up to $66 \%$ were achieved with $1.3 \mathrm{~nm}$ Mo and $0.6 \mathrm{~nm}$ thick Ru. This Ru thickness is believed to be too thin for oxidation protection. $\mathrm{Ru}$ on Mo capping layer design is a better oxidation barrier than $\mathrm{Si}$ cap, however it is not practical because of its low initial reflectivity.

\subsubsection{Ru on B4C}

So far the best results were achieved with $\mathrm{Ru}$ capped multilayer in which $\mathrm{B}_{4} \mathrm{C}$ was used as a diffusion barrier between $\mathrm{Ru}$ and $\mathrm{Si}$. The best oxidation protection was obtained on multilayers that consisted of a standard 40 bilayer $\mathrm{Mo} / \mathrm{Si}$ multilayer terminated with a thinner, $2.0 \mathrm{~nm}$ Si layer on the top of which we deposited $2.0 \mathrm{~nm} \mathrm{~B} \mathrm{~B}_{4} \mathrm{C}$ and $2.3 \mathrm{~nm} \mathrm{Ru}$. The initial reflectance of so capped multilayers was $65.88 \%$ at $13.31 \mathrm{~nm}$ but the reflectance measured one month after the deposition decreased to $65.34 \%$ at $13.31 \mathrm{~nm}$. Depth profile shows a very thin Ru oxide (Fig. 7). The reason why we were not able to plot carbon depth profile is that the electron binding energy for carbon and ruthenium peaks almost overlaps. After the exposure the reflectance of this sample was still $65.88 \%$ at $13.31 \mathrm{~nm}$. However, the reflectance in the non-exposed area is lower $(65.34 \%)$. We do not have enough data to understand this but one possible explanation is that the ruthenium oxide is volatile. Additional experiments are being planned to study this further.

\section{SUMMARY}

The success of Extreme Ultraviolet Lithography (EUVL) is greatly dependent on the performance and stability of $\mathrm{Mo} / \mathrm{Si}$ multilayer coatings. These multilayers need to maintain high reflectance in realistic lithography tool environment in order to commercially viable.

In this paper we outlined the requirements for high performance EUV multilayers and presented EUVL roadmap for multilayer coatings. We developed above $70 \%$ reflectance multilayers using interface-engineering. Instead of using a simple, two layer multilayer we developed a more sophisticated multilayer system in which Mo and Si layers are separated with low $\mathrm{Z}$ material interlayers (boron carbide). In addition we studied different capping layers for their reflectance stability in the presence of EUV light and water vapor. The exposures were actually done with electron beam exposures assuming that the low energy secondary electrons are causing the damage and that their spectrum is somewhat similar to the spectrum of low energy secondary electrons created by EUV light. In this study we addressed only the reflectance loss to oxidation and the best protection was observed on Ru capped multilayers with boron carbide diffusion barrier between Ru and last Si layer.

\section{ACKNOWLEDGEMENTS}

The authors wish to thank Chris Walton, Mark Wall, Fred Grabner, Steven Liapis (LLNL), Erica Salinas (MIT), Mike Malinowski (SNL), and Andy Aquila (LBNL) for their technical support of this work. The authors would also like to 
acknowledge contributions made by Tai Nguyen earlier in this project. We would like to thank Don Sweeney and Daniel G. Stearns (LLNL) for helpful discussions.

This work was performed under the auspices of the U.S. Department of Energy by the Lawrence Livermore National Laboratory under Contract No. W-7405-ENG-48. Funding was provided by the Extreme Ultraviolet Limited Liability Company (EUV. LLC) under a Cooperative Research and Development Agreement (CRADA).

\section{REFERENCES}

1. C. Montcalm, S. Bajt, P. B. Mirkarimi, E. Spiller, F. J. Weber, and J. A. Folta, "Multilayer reflective coatings for extreme-ultraviolet lithography", in Emerging Lithographic Technologies II, SPIE 3331, 42-51 (1998).

2. E. Louis, A. E. Yakshin, P. C. Görts, S. Oestreich, R. Stuik, E. L. G. Maas, M. J. H. Kessels, F. Bijkerk, M. Haidl, S. Mullender, M. Mertin, D. Schmitz, F. Scholze, and G. Ulm, "Progress in Mo/Si multilayer coating technology for EUV optics", in Emerging Lithographic Technologies IV, SPIE 3997, 406-411 (2000).

3. T. Feigl, H. Lauth, S. Yulin, N. Kaiser, "Heat resistance of EUV multilayer mirrors for long-time applications", Microelectronic Engineering 57-58, 3-8 (2001).

4. J. A. Folta, S. Bajt, T. W. Barbee Jr., R. F. Grabner, P. B. Mirkarimi, T. Nguyen, M. A. Schmidt, E. Spiller, C. C. Walton, M. Wedowski, and C. Montcalm, “ Advances in multilayer reflective coatings for extreme-ultraviolet lithography", SPIE 3676, $702-709$ (1999).

5. R. Soufli, E. Spiller, M. A. Schmidt, J. C. Davidson, R. F. Grabner, E. M. Gullikson, B. B. Kaufmann, S. L. Baker, H. N. Chapman, R. M. Hudyma, J. S. Taylor, C. C. Walton, C. Montcalm, J. A. Folta, "Mutlilayer optics for an extreme ultraviolet lithography tool with $70 \mathrm{~nm}$ resolution", in Emerging Lithographic Technologies $V$, SPIE 4343 (2001).

6. D. A. Tichenor, A. K. Ray-Chaudhuri, W. C. Replogle, R. H. Stulen, G. D. Kubiak, P. D. Rockett, L. E. Klebanoff, K. L. Jefferson, A. H. Leung, J. B. Wronosky, L. C. Hale, H. N. Chapman, J. S. Taylor, J. A. Folta, C. Montcalm, R. Soufli, E. Spiller, K. Blaedel, G. E. Sommargren, D. W. Sweeney, P. Naulleau, K. A. Goldberg, E. M. Gullikson, J. Bokor, P. J. Batson, D. T. Attwood, K. H. Jackson, S. D. Hector, C. W. Gwyn, and P-Y. Yan, "System integration and performance of the EUV engineering test stand", in Emerging Lithographic Technologies V, SPIE 4343, 19-37 (2001).

7. J. H. Underwood and E. M. Gullikson, "High-resolution, high-flux, user friendly VLS beamline at the ALS for the 50$1300 \mathrm{eV}$ energy region:, J. Electr. Spectr. Rel. Phenom. 92, 265-272 (1998).

8. A. K. Petford-Long, M. B. Stearns, C. -H. Chang, S. R. Nutt, D. G. Stearns, N. M. Ceglio, and A. M. Hawryluk, J. Appl. Phys. 61, 1422 (1987).

9. R. Stuik, E. Louis, A. E. Yakshin, P. C. Görts, E. L. Maas, F. Bijkerk, D. Schmitz, F. Scholze, G. Ulm, M. Haidl, "Peak and integrated reflectivity, wavelength and gamma optimization of $\mathrm{Mo} / \mathrm{Si}$, and $\mathrm{Mo} / \mathrm{Be}$ multilayer, multielement optics for extreme ultraviolet lithography", J. Vac. Sci. technol. B 17, 2998-3002 (1999).

10. H. Takenaka, H. Ito, T. Kawamura, "Characteristics and thermal behavior of $\mathrm{Mo} / \mathrm{Si}$ multilayer soft $\mathrm{x}$-ray mirrors with interleaved barrier-layers", X-ray Lasers 1998, Inst. of Phys. Conf. Ser. 159, 605-608 (1999).

11. A. Keppel, R. Schlatmann, J. Verhoeven, "Multilayer mirror with a variable refractive index", US patent 5,551,587, Sept. 3, 1996.

12. A. Anopchenko, M. Jergel, E. Majková, Š. Luby, V. HolÝ, A. Aschentrup, I. Kolina, Y. Cheol Lim, G. Haindl, U.

Kleineberg, U. Heinzmann, "Effect of substrate heating and ion beam polishing on the interface quality in Mo/Si multilayers

- X-ray comparative study", Physica B 305, 14-20 (2001).

13. St. Braun, R. Dietsch, M. Haidl, Th. Holz, H. Mai, S. Müllender, R. Scholz, "Mo/Si-multilayers for EUV applications prepared by Pulsed Laser Deposition (PLD)", Microelectronic Engineering 57-58, 9-15 (2001).

14. S. Bajt, D. G. Stearns, P. A. Kearney, "Investigation of the amorphous-to-crystalline transition in Mo/Si multilayers", J. Appl. Phys. 90, 1017-1025 (2001).

15. D. L. Windt, R. Hull, and, W. K. Waskiewicz, "Interface imperfections in metal/Si multilayers", J. Appl. Phys. 71, 26752678 (1992).

16. D. G. Stearns, R. S. Rosen, S. P. Vernon, "High-performance multilayer mirrors for soft x-ray projection lithography", SPIE 1547, 2-13, 1991.

17. P. B. Mirkarimi, S. Bajt, and M. A. Wall, "Mo/Si and Mo/Be multilayer thin films on Zerodur substrates for extremeultraviolet lithography", Appl. Opt. 39, 1617-1625 (2000).

18. M. Wedowski, S. Bajt, J. A. Folta, E. M. Gullikson, U. Kleineberg, L. E. Klebanoff, M. E. Malinowski, W. M. Clift, "Lifetime studies of $\mathrm{Mo} / \mathrm{Si}$ and $\mathrm{Mo} / \mathrm{Be}$ multilayer coatings for extreme ultraviolet lithography", in $E U V$, X-ray, and Neutron Optics and Sources, SPIE 3767, 217-224 (1999).

19. D. P. Gaines, R. C. Spitzer, N. M. Ceglio, M. Krumrey, and G. Ulm, "Radiation hardness of molybdenum silicon multilayers designed for use in a soft-x-ray projection lithography system", Appl. Opt. 32, 6991-6998 (1993).

This work was performed under the auspices of the U.S. Department of Energy by the University of California, Lawrence Livermore National Laboratory under Contract No. W-7405-Eng-48. 
20. S. Oestreich, R. Klein, F. Scholze, J. Jonkers, E. Louis, A. Yakshin, P. Görts, G. Ulm, M. Haidl, and F. Bijkerk, "Multilayer reflectance during exposure to EUV radiation", in Soft X-ray and EUV imaging systems, W. M. Kaiser R. H. Stulen, Editors, SPIE 4146, 64-71 (2000).

21. M. Malinowski, private communications, 2001.

22. M. Singh, and J. J. M. Braat, "Capping layers for extreme-ultraviolet multilayer interference coatings", Opt. Lett. 26, 259-261 (2001).

23. L. Klebanoff, private communications, 2001. 